\title{
A Novel Design of Low Power 4:2 Compressor using Adiabatic Logic
}

\author{
Shaswat Singh Bhardwaj, Vishal Moyal \\ ${ }^{1,2}$ Department of Electronics \& Telecommunication Engineering, SSTC, SSGI (FET) Bhilai, India
}

\begin{abstract}
The purpose of the project is to design an adiabatic logic based low power 4:2 Compressor on the application of "Two Phase Clocked Adiabatic Static Logic (2PASCL) technique”, which shows the lowest power dissipation between different adiabatic logic families. It works on the principle of charge reversible logic. The present technique has smallest power dissipation relative to the standard CMOS design style by using different design specification such as different input signal switching frequency and supply voltage. The simulation is performed on S-edit of Tanner tool at 90nm BSIM4 technology.
\end{abstract}

Keywords: Adiabatic logic, Sinusoidal power supply, two phase power clock, energy recovery logic, 2PASCL technique, S-edit, Odd detector, compressor

\section{Introduction}

Now days, the movable devices are increasingly used by the everyday life. There is a continuous increase in these portable equipments, such as laptops, cell phones etc. With the gradual increase in complexity and functionality of these portable devices, the power dissipation will also increase. There are various sources of power dissipation in digital CMOS circuits such as switching power, leakage power and short circuit power dissipation. This power dissipation can be reduced by reducing the supply voltage, power gating and multi-threshold libraries. But this technique is not sufficient to fulfill today's power needs, hence another approach can be used to reduce power dissipation that is called as Adiabatic Logic. In this technique, oscillating power supplies may be utilized instead of constant supply voltage and charge stored in an output capacitor is reused instead of charge expending as in a conventional CMOS circuit. Hence, the total energy can be conserved.

\section{Adiabatic 2PASCL Technique}

The word "Adiabatic" is used in thermodynamics system that does not transfer energy to the environment, so that charge transfer out of the module is comparable to zero. But in everyday growth of computing, such optimal process cannot be possible because of the existence of dissipative elements like resistances in a circuit. Therefore, the Adiabatic logic is used in ultra low power purpose for which conventional energy is confined and speed is not critical such as biomedical, robotics, space, deep sea, etc [1].

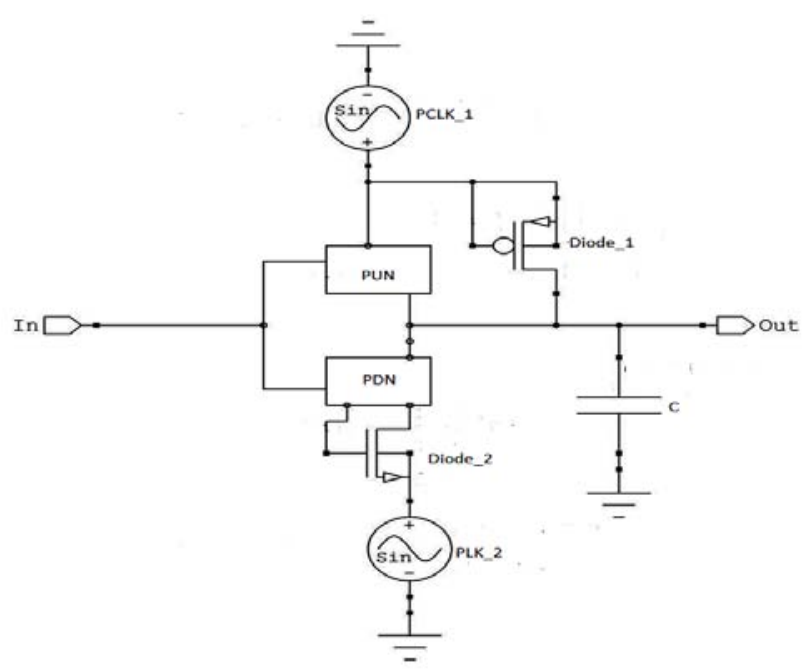

Figure 1: basic 2PASCL adiabatic circuits

From Fig. 1 the construction of 2PASCL logic based circuits consists of two powers clock PCLK_1 and PCLK_2 respectively and there is one eighteen degree phase reversal among consecutive power clocks. The above circuit also contains two diodes in its construction where Diode_1 is connected with PCLK_1 and output terminal and Diode_2 is connected with PDN and PCLK_2, so that both diodes enhance the discharging velocity of internal signal nodes. The operation of adiabatic 2PASCL circuits can be divided into two phases. In charging phase, when the intake voltage is low then PUN is in ON state and PDN is in OFF state which results in charging the output load capacitor equal to the supply voltage. The charging phase is illustrated in Fig. 2. 


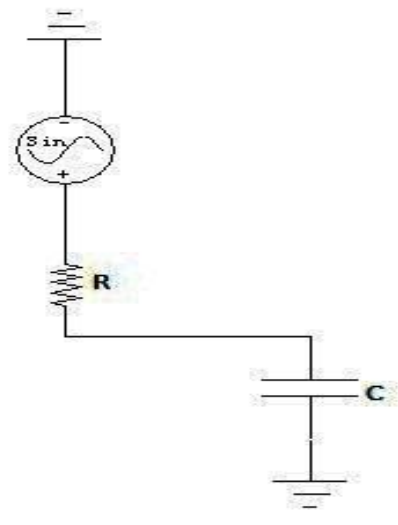

Figure 2: Charging in 2PASCL adiabatic logic

During discharging phase, when the input signal is high then PDN is ON and PUN is in OFF state which result in charge reserved in the output load capacitor can be retrieve instead of dissipated, in the conventional CMOS technique. The discharging phase is illustrated in Fig. 3.

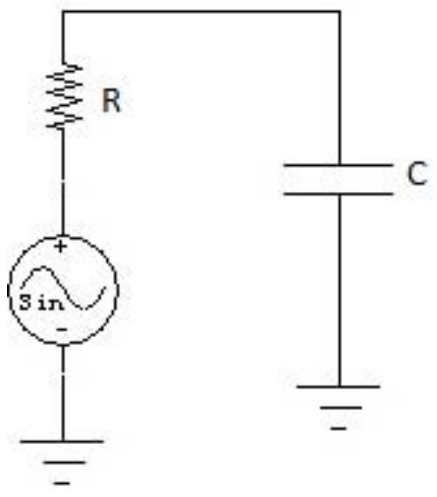

Figure 3: Discharging in 2PASCL adiabatic logic

\section{Multiplexer}

A multiplexer is also abbreviated as "MUX". It is a combinational logic circuit that consists of several input lines, select lines and a single output line. A single input line can be routed to the output line by choosing a proper combination of select lines. Multiplexers are similar to a speedily moving multiple position rotary switch which controls multiple input lines one at a time to the output.

\subsection{2 to 1 line Multiplexer:}

A 2 to 1 line multiplexer has two inputs but a single output. Under control of single selection line, one of the input signals is passed to the output. Fig. 4 shows the schematic symbol of 2 to 1 line multiplexer. The truth table of 2 to 1 line multiplexer is given in Table 1

Table 1: Table of 2 To 1 Line Multiplexer

\begin{tabular}{|c|c|}
\hline Select line & Data output \\
\hline $\mathrm{S}_{0}$ & $\mathrm{I}_{0}$ \\
\hline $\mathrm{S}_{1}$ & $\mathrm{I}_{1}$ \\
\hline
\end{tabular}

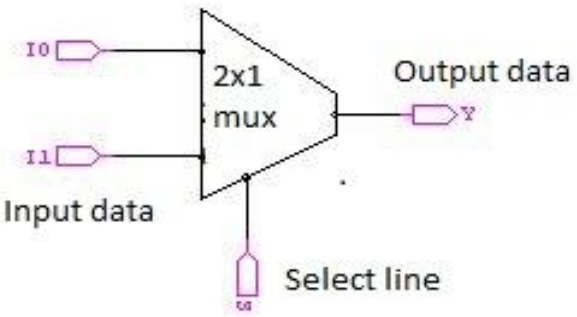

Figure 4: Symbol of 2 to 1 line multiplexer

From the propositional function, the output logic can be expressed as min-terms and are given below in Eq. 1 .

$$
\mathrm{Y}=\overline{\mathrm{S}}_{0} \mathrm{I}_{0}+\mathrm{S}_{1} \mathrm{I}_{1}
$$

Where I and $\mathrm{S}$ are data input and select line respectively.

\section{Exclusive - Or (EX-OR) Gate}

The logical operation of a two-input EX-OR gate is that its output is at logic high, only when one of its inputs is high. Under the conditions, when both the inputs have the logic 0 state, or when both the inputs have the logic 1 state, the output has a logic 0 state. It is called an Anti-coincidence or Inequality Detector.

The input variables are represented by $\mathrm{A}$ and $\mathrm{B}$ and the output variable is represented by $\mathrm{X}$. The output expression of this gate is written as given in Eq. (2).

$$
\mathrm{X}=\mathrm{A} \overline{\mathrm{B}}+. \mathrm{B}=\mathrm{A} \oplus \mathrm{B}
$$

The schematic symbol of EX-OR gate is illustrated in Fig. 5. And the truth table of EX-OR gate is given in Table II.

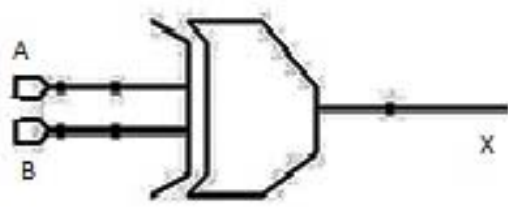

Figure 5: Symbol of EX-OR gate

Table 2: Truth Table Two Input ex-or gate

\begin{tabular}{|c|c|c|}
\hline \multicolumn{2}{|c|}{ Inputs } & Output \\
\hline $\mathrm{A}$ & $\mathrm{B}$ & $\mathrm{X}=\mathrm{A} \overline{\mathrm{B}}+. \mathrm{B}$ \\
\hline 0 & 0 & 0 \\
\hline 0 & 1 & 1 \\
\hline 1 & 0 & 1 \\
\hline 1 & 1 & 0 \\
\hline
\end{tabular}

\section{Compressor}

Compressors are the basic building blocks of high accuracy and high speed multipliers, arithmetic and digital signal processing (DSP) applications. A 4:2 compressor consists of five inputs namely $\mathrm{X} 1, \mathrm{X}_{2}, \mathrm{X}_{3}, \mathrm{X}_{4}$ and $\mathrm{C}_{\mathrm{IN}}$. It produces a sum bit (S), a carry bit (C), and a carry propagate bit (Cout). The Carry bit from position to right is denoted as $\mathrm{C}_{\mathrm{IN}}$, while the carry bit into higher position is denoted as Cout. To avoid carry propagation the value of $\mathrm{C}_{\mathrm{OUT}}$ depends only on $\mathrm{X}_{1}, \mathrm{X}_{2}$, 


\section{International Journal of Science and Research (IJSR) \\ ISSN (Online): 2319-7064}

Index Copernicus Value (2013): 6.14 | Impact Factor (2015): 6.391

$\mathrm{X}_{3}$ and $\mathrm{X}_{4}$. It is independent of $\mathrm{C}_{\mathrm{IN}}$ the block diagram is shown in Fig. 6 [2].

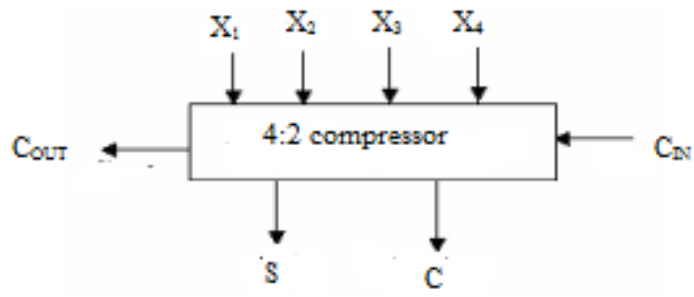

Figure 6: Symbol of 4:2 Compressor

The 4:2 compressor could be realized by different combinations of EX-OR gates and multiplexers. It is composed of six modules: four 2-input EX-OR gates and two 2 to 1 line multiplexers. The logic level decomposition is shown in Fig. 7.

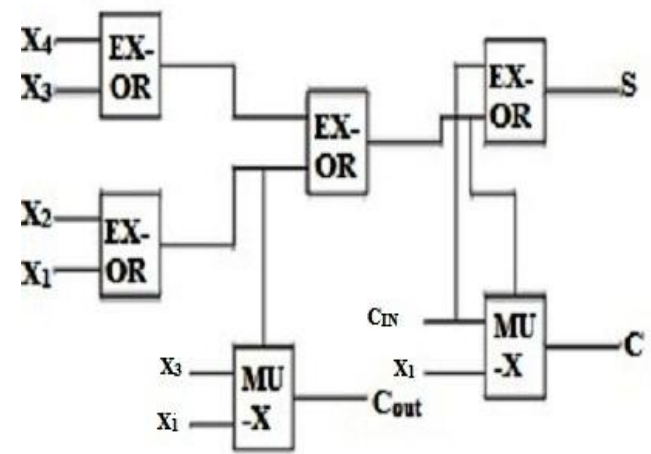

Figure 7: Logic level decomposition of 4:2 compressors

The output expression of 4:2 compressor are given by the following equations.

$$
\begin{aligned}
& \mathrm{S}=\mathrm{X}_{1} \oplus \mathrm{X}_{2} \oplus \mathrm{X}_{3} \oplus \mathrm{X}_{4} \oplus \mathrm{C}_{\mathrm{IN}} \\
& \mathrm{C}=\left(\mathrm{X}_{1} \oplus \mathrm{X}_{2}\right) \mathrm{X}_{3}+\left(\mathrm{X}_{1} \oplus \mathrm{X}_{2}\right) \mathrm{X}_{1} \\
& \mathrm{C}_{\mathrm{OUT}} \frac{\left(\mathrm{X}_{1} \oplus \mathrm{X}_{2} \oplus \mathrm{X}_{3} \oplus \mathrm{X}_{4}\right) \mathrm{C}_{\mathrm{IN}}+}{\left(\mathrm{X}_{1} \oplus \mathrm{X}_{2} \oplus \mathrm{X}_{3} \oplus \mathrm{X}_{4}\right) \mathrm{X}_{4}}
\end{aligned}
$$

\begin{tabular}{|c|c|c|c|c|c|c|c|c|}
\hline \multicolumn{4}{|c|}{ inputs } & \multicolumn{2}{|c|}{$\mathrm{C}_{\mathrm{IN}}=0$} & \multicolumn{2}{|c|}{$C_{I N}=1$} & \multirow{2}{*}{$\mathrm{C}_{\text {OUT }}$} \\
\hline $\mathrm{X}_{1}$ & $\mathrm{X}_{2}$ & $\mathrm{X}_{3}$ & $X_{4}$ & $\mathrm{C}$ & $\mathrm{S}$ & $\mathrm{C}$ & $\mathrm{S}$ & \\
\hline 0 & 0 & 0 & 0 & 0 & 0 & 0 & 1 & 0 \\
\hline 0 & 0 & 0 & 1 & \multirow{4}{*}{0} & \multirow{4}{*}{1} & \multirow{4}{*}{1} & \multirow{4}{*}{0} & \multirow{4}{*}{0} \\
\hline 0 & 0 & 1 & 0 & & & & & \\
\hline 0 & 1 & 0 & 0 & & & & & \\
\hline 1 & 0 & 0 & 0 & & & & & \\
\hline 0 & 0 & 1 & 1 & \multirow{6}{*}{0} & \multirow{6}{*}{0} & \multirow{6}{*}{0} & \multirow{6}{*}{1} & \multirow{6}{*}{1} \\
\hline 0 & 1 & 1 & 0 & & & & & \\
\hline 1 & 1 & 0 & 0 & & & & & \\
\hline 0 & 1 & 0 & 1 & & & & & \\
\hline 1 & 0 & 1 & 0 & & & & & \\
\hline 1 & 0 & 0 & 1 & & & & & \\
\hline 0 & 1 & 1 & 1 & \multirow{4}{*}{0} & \multirow{4}{*}{1} & \multirow{4}{*}{1} & \multirow{4}{*}{0} & \multirow{4}{*}{1} \\
\hline 1 & 1 & 1 & 0 & & & & & \\
\hline 1 & 1 & 0 & 1 & & & & & \\
\hline 1 & 1 & 1 & 0 & & & & & \\
\hline 1 & 1 & 1 & 1 & 1 & 0 & 1 & 1 & 1 \\
\hline
\end{tabular}

Table 3: Truth Table of 4:2 Compressors

\section{Design of 4:2 Compressor}

The 4:2 compressor can be designed by using 2 to 1 line multiplexer and two input EX-OR gate by the application of CMOS and 2PASCL logic technique given in below figures.

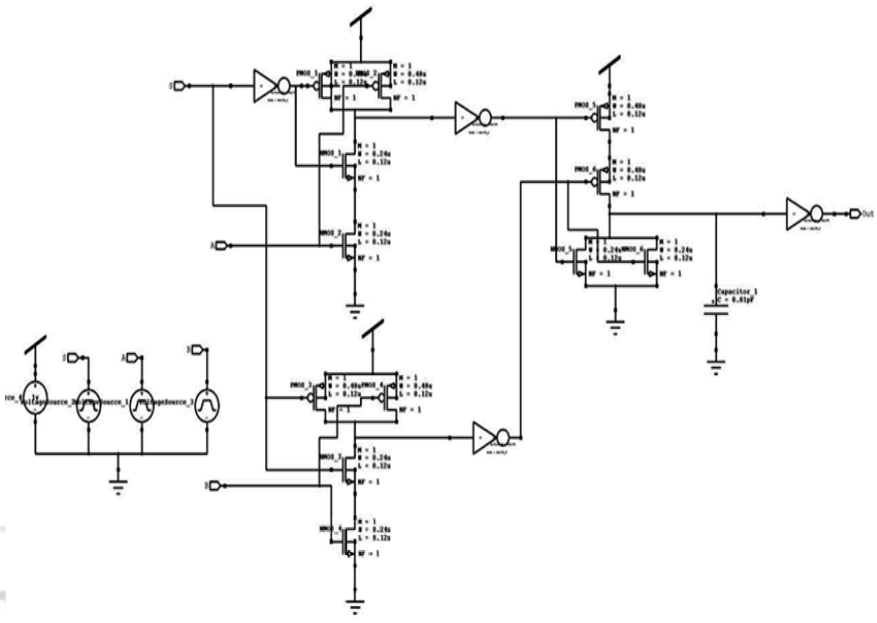

Figure 8: Schematic of 2 to1 line multiplexer using CMOS logic

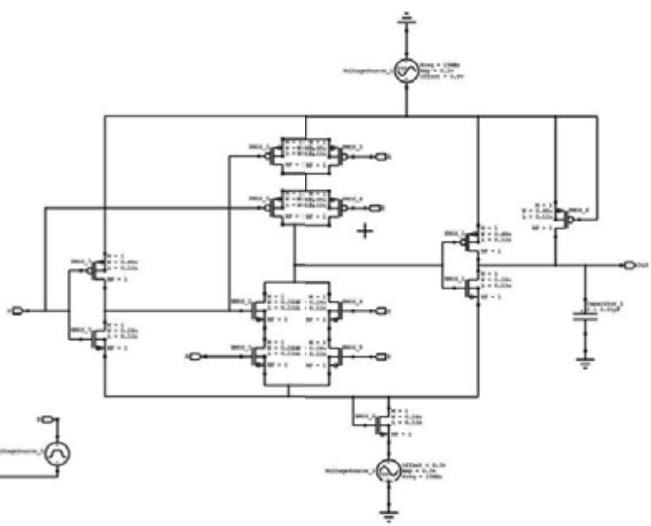

Figure 9: Schematic of 2PASCL logic based 2 to 1 line multiplexer

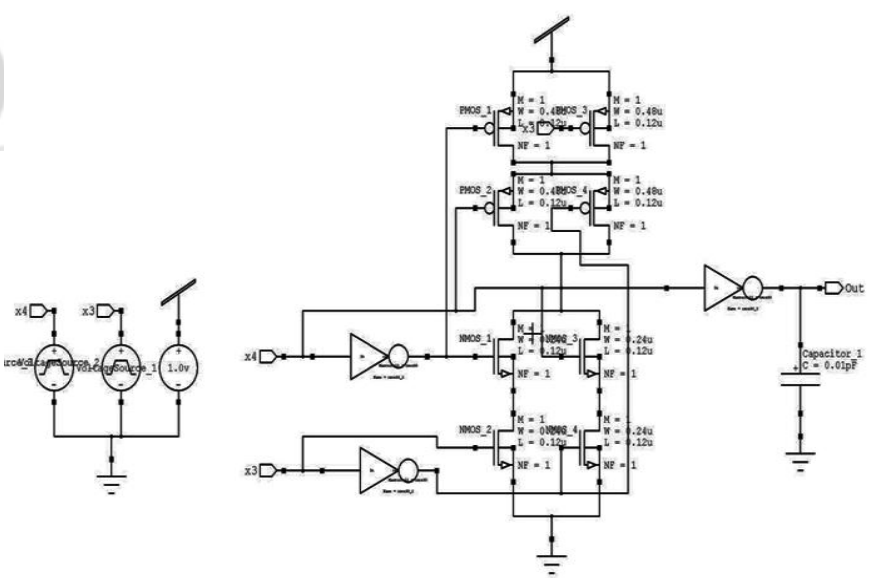

Figure 10: Schematic of EX-OR gate using CMOS logic 


\section{International Journal of Science and Research (IJSR)}

ISSN (Online): 2319-7064

Index Copernicus Value (2013): 6.14 | Impact Factor (2015): 6.391

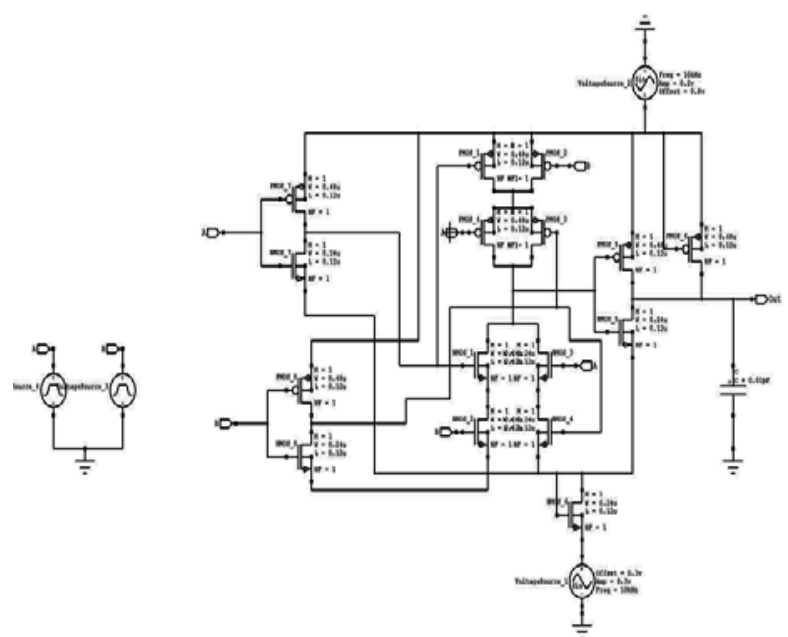

Figure 11: Schematic of 2PASCL logic based EX-OR gate

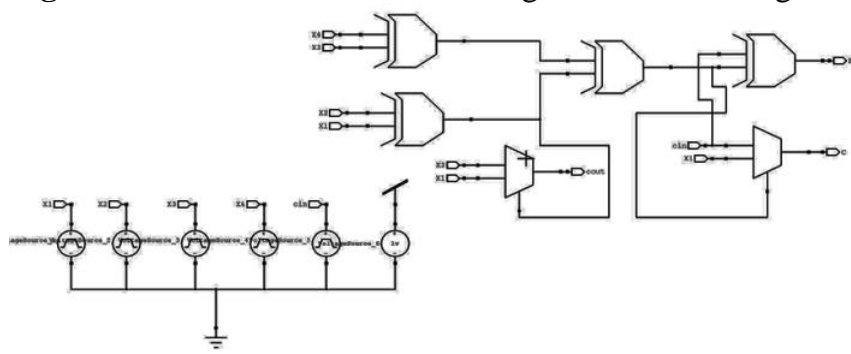

Figure 12: 4:2 Compressor by using CMOS logic

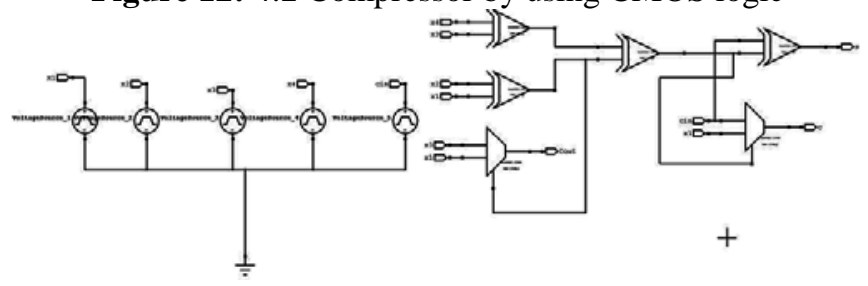

Figure 13: Adiabatic 2PASCL logic based 4:2 Compressors

\section{Simulation Results}

The simulation is performed on Tanner EDA tool using 90nm technology. The Tanner tool consists of S-edit, Tspice, W-edit tools. S-edit is a schematic entry tool that is used to verify the circuits, T-Spice provides the simulation of the circuits and $\mathrm{W}$-edit provides the real time waveform viewing. Below figures show the simulated waveform of 2 to 1 line multiplexer, EX-OR gate and 4:2 compressor using conventional CMOS and 2PASCL logic respectively.

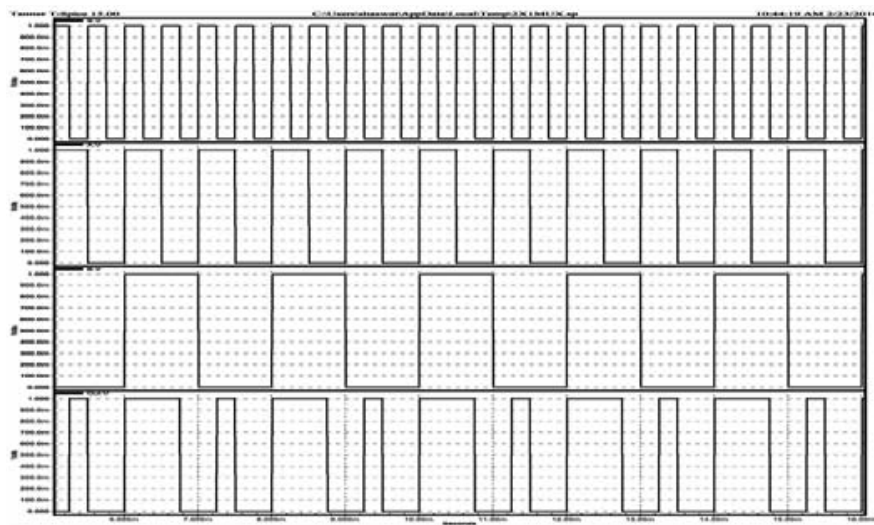

Figure 14: Simulation waveform of 2 to 1 line multiplexer using CMOS logic

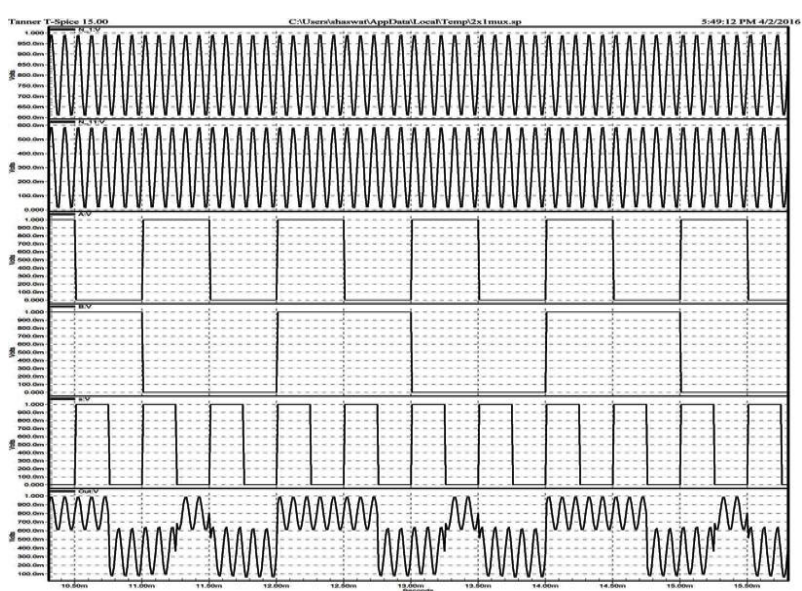

Figure 15: Simulation output waveform of 2 to 1 line multiplexer using 2PASCL logic

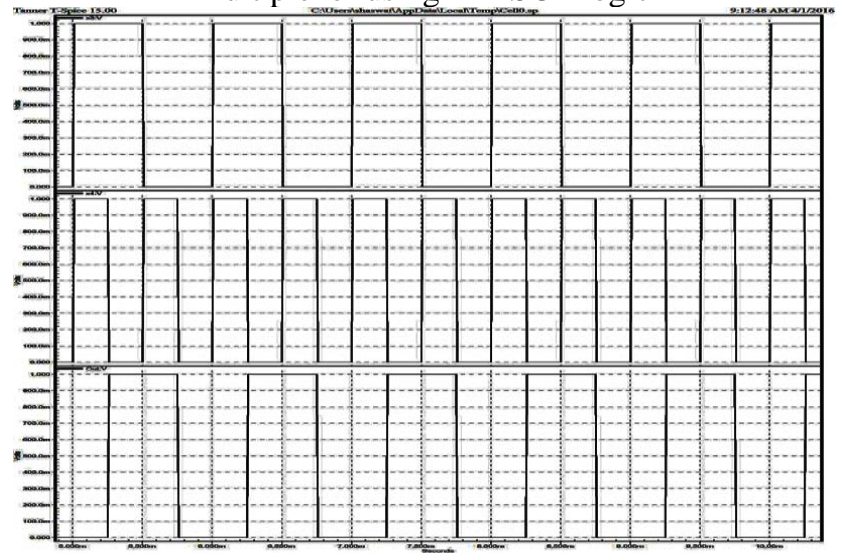

Figure 16: Simulated waveform of EX - OR gate using CMOS logic

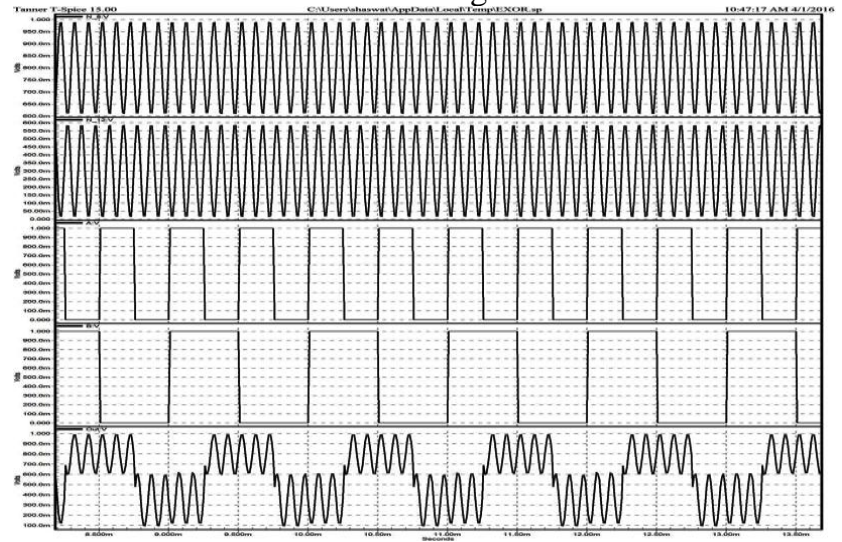

Figure 17: Simulated waveform of EX-OR gate using 2PASCL logic

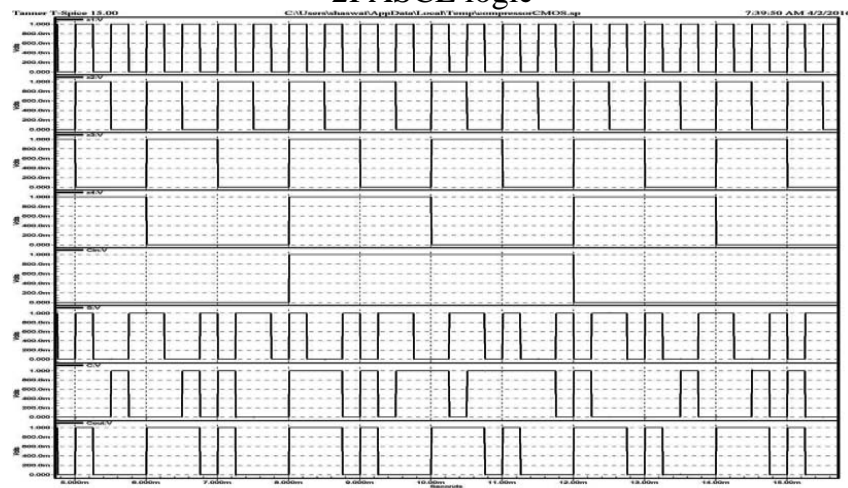

Figure 18: Simulated waveform of 4:2 compressor using CMOS logic

Volume 5 Issue 4, April 2016

www.ijsr.net 


\section{International Journal of Science and Research (IJSR) ISSN (Online): 2319-7064}

Index Copernicus Value (2013): 6.14 | Impact Factor (2015): 6.391

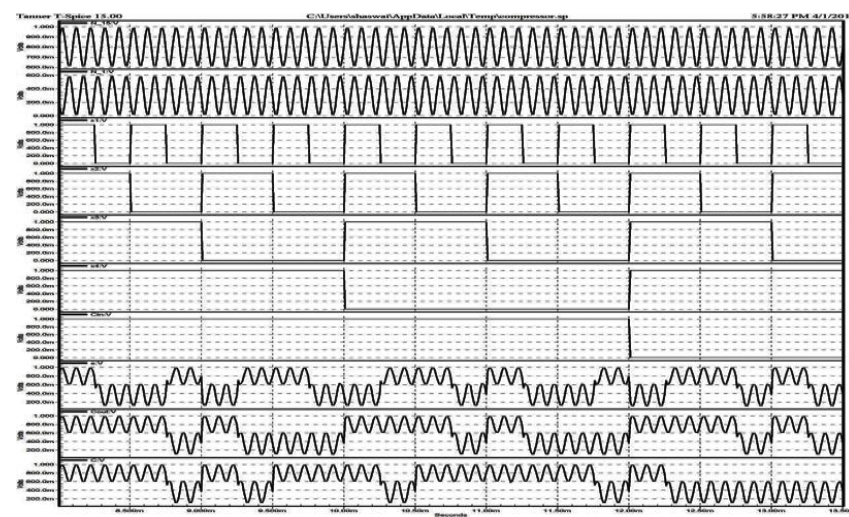

Figure 19: Simulated waveform of 4:2 compressors using 2PASCL logic

\section{Comparison of Results}

Table 4: Comparison of Proposed and CMOS Logic Based 2 To 1 Line Multiplexer

\begin{tabular}{|c|c|c|c|c|}
\hline $\begin{array}{l}\text { Logic } \\
\text { families }\end{array}$ & $\begin{array}{c}\text { Change in } \\
\text { supply } \\
\text { voltage }\end{array}$ & $\begin{array}{c}\text { Average } \\
\text { power } \\
\text { dissipation }\end{array}$ & $\begin{array}{l}\text { Change in } \\
\text { input } \\
\text { frequency }\end{array}$ & $\begin{array}{c}\text { Average } \\
\text { power } \\
\text { dissipation }\end{array}$ \\
\hline \multirow{5}{*}{ CMOS } & $1.2 \mathrm{~V}$ & $3.24 \mu \mathrm{W}$ & $2 \mathrm{KHz}$ & $0.523 \mu \mathrm{W}$ \\
\hline & $1.4 \mathrm{~V}$ & $14.4 \mu \mathrm{W}$ & \multirow{2}{*}{$5 \mathrm{KHz}$} & \multirow{2}{*}{$0.544 \mu \mathrm{W}$} \\
\hline & $1.6 \mathrm{~V}$ & $57.9 \mu \mathrm{W}$ & & \\
\hline & $1.8 \mathrm{~V}$ & $130.6 \mu \mathrm{W}$ & \multirow{2}{*}{$10 \mathrm{KHz}$} & \multirow{2}{*}{$1.19 \mu \mathrm{W}$} \\
\hline & $2.0 \mathrm{~V}$ & $201.8 \mu \mathrm{W}$ & & \\
\hline \multirow{5}{*}{ 2PASCL } & $1.2 \mathrm{~V}$ & $3.22 \mathrm{nW}$ & $2 \mathrm{KHz}$ & $0.76 \mathrm{nW}$ \\
\hline & $1.4 \mathrm{~V}$ & $8.71 \mathrm{nW}$ & \multirow{2}{*}{$5 \mathrm{KHz}$} & \multirow{2}{*}{$0.86 \mathrm{nW}$} \\
\hline & $1.6 \mathrm{~V}$ & $78.3 \mathrm{nW}$ & & \\
\hline & $1.8 \mathrm{~V}$ & $953.06 \mathrm{nW}$ & \multirow{2}{*}{$10 \mathrm{KHz}$} & \multirow{2}{*}{$0.94 \mathrm{nW}$} \\
\hline & $2.0 \mathrm{~V}$ & $2377.5 \mathrm{nW}$ & & \\
\hline
\end{tabular}

In Table 4, the proposed logic based multiplexer can save 99.92\% And $98.82 \%$ of power with respect to CMOS logic based multiplexer at $10 \mathrm{KHz}$ input frequency and $2.0 \mathrm{~V}$ supply voltage respectively.

Table 5: Comparison of Proposed And CMOS Logic Based EX-OR Gate

\begin{tabular}{|c|c|c|c|c|}
\hline $\begin{array}{c}\text { Logic } \\
\text { families }\end{array}$ & $\begin{array}{c}\text { Change in } \\
\text { supply } \\
\text { voltage }\end{array}$ & $\begin{array}{c}\text { Average } \\
\text { power } \\
\text { dissipation }\end{array}$ & $\begin{array}{l}\text { Change in } \\
\text { input } \\
\text { frequency }\end{array}$ & $\begin{array}{c}\text { Average } \\
\text { power } \\
\text { dissipation }\end{array}$ \\
\hline \multirow{5}{*}{ CMOS } & $1.2 \mathrm{~V}$ & $4.41 \mu \mathrm{W}$ & $2 \mathrm{KHz}$ & $0.3 \mu \mathrm{w}$ \\
\hline & $1.4 \mathrm{~V}$ & $18 \mu \mathrm{W}$ & \multirow{2}{*}{$5 \mathrm{KHz}$} & \multirow{2}{*}{$0.76 \mu \mathrm{w}$} \\
\hline & $1.6 \mathrm{~V}$ & $69.2 \mu \mathrm{W}$ & & \\
\hline & $1.8 \mathrm{~V}$ & $160 \mu \mathrm{W}$ & \multirow{2}{*}{$10 \mathrm{KHz}$} & \multirow{2}{*}{$1.50 \mu \mathrm{w}$} \\
\hline & $2.0 \mathrm{~V}$ & $288 \mu \mathrm{W}$ & & \\
\hline \multirow{5}{*}{ 2PASCL } & $1.2 \mathrm{~V}$ & $40 \mathrm{nW}$ & $2 \mathrm{KHz}$ & $1.64 \mathrm{nw}$ \\
\hline & $1.4 \mathrm{~V}$ & $2109.2 \mathrm{nW}$ & \multirow{2}{*}{$5 \mathrm{KHz}$} & \multirow{2}{*}{$2.33 \mathrm{nw}$} \\
\hline & $1.6 \mathrm{~V}$ & $8909.6 \mathrm{nW}$ & & \\
\hline & $1.8 \mathrm{~V}$ & $9322 \mathrm{nw}$ & \multirow{2}{*}{$10 \mathrm{KHZ}$} & \multirow{2}{*}{$3.60 \mathrm{nw}$} \\
\hline & $2.0 \mathrm{~V}$ & $10191.4 \mathrm{nw}$ & & \\
\hline
\end{tabular}

In Table 5, the proposed logic based EX-OR gate can save $99.76 \%$ and $96.46 \%$ of power with respect to CMOS logic based EX-OR gate at $10 \mathrm{KHZ}$ input frequency and $2.0 \mathrm{~V}$ supply voltage respectively.
Table 6: Result of 4:2 Compressor Using CMOS And 2PASCL Logic

\begin{tabular}{|c|c|c|c|c|}
\hline $\begin{array}{c}\text { Logic } \\
\text { families }\end{array}$ & $\begin{array}{c}\text { Change in } \\
\text { supply } \\
\text { voltage }\end{array}$ & $\begin{array}{c}\text { Average } \\
\text { power } \\
\text { dissipation }\end{array}$ & $\begin{array}{c}\text { Change in } \\
\text { input } \\
\text { frequency }\end{array}$ & $\begin{array}{c}\text { Average } \\
\text { power } \\
\text { dissipation }\end{array}$ \\
\hline \multirow{5}{*}{ CMOS } & $1.2 \mathrm{~V}$ & $7.19 \mu \mathrm{W}$ & $2 \mathrm{KHz}$ & $0.422 \mu \mathrm{W}$ \\
\hline & $1.4 \mathrm{~V}$ & $45.1 \mu \mathrm{W}$ & \multirow{2}{*}{$5 \mathrm{KHz}$} & \multirow{2}{*}{$1.02 \mu \mathrm{W}$} \\
\hline & $1.6 \mathrm{~V}$ & $206.4 \mu \mathrm{W}$ & & \\
\hline & $1.8 \mathrm{~V}$ & $491.9 \mu \mathrm{W}$ & \multirow{2}{*}{$10 \mathrm{KHz}$} & \multirow{2}{*}{$2.01 \mu \mathrm{W}$} \\
\hline & $2.0 \mathrm{~V}$ & $895.3 \mu \mathrm{W}$ & & \\
\hline \multirow{5}{*}{ 2PASCL } & $1.2 \mathrm{~V}$ & $128 \mathrm{nW}$ & $2 \mathrm{KHz}$ & $8.16 n W$ \\
\hline & $1.4 \mathrm{~V}$ & $6065.0 \mathrm{nW}$ & \multirow{2}{*}{$5 \mathrm{KHz}$} & \multirow{2}{*}{$10.01 \mathrm{nW}$} \\
\hline & $1.6 \mathrm{~V}$ & $30224.4 \mathrm{nW}$ & & \\
\hline & $1.8 \mathrm{~V}$ & $31866.5 \mathrm{nW}$ & \multirow{2}{*}{$10 \mathrm{KHz}$} & \multirow{2}{*}{$12.4 \mathrm{nW}$} \\
\hline & $2.0 \mathrm{~V}$ & $35082.0 \mathrm{nW}$ & & \\
\hline
\end{tabular}

In Table 6, the proposed logic based 4:2 compressor can save 99.38\% And $96.08 \%$ of power with respect to CMOS logic based $4: 2$ compressor at $10 \mathrm{KHz}$ input frequency and $2.0 \mathrm{~V}$ supply voltage respectively.

\section{Conclusion}

From the results, it is concluded that the 2PASCL logic based 4:2 compressor is more energy efficient as compared to CMOS logic based compressor. The proposed compressor has power saving of $99.38 \%$ and $96.08 \%$ respectively as compared to static CMOS logic based $4: 2$ compressor at 10 $\mathrm{KHz}$ input signal frequency and 2.0V supply voltage.

\section{References}

[1] Ajit Pal, "Low Power VLSI Circuits and systems" Springer India 2015.

[2] Riya Garg, Suman Nehra, B.P. singh, "Low Power 4-2 Compressor for Arithmetic Circuits", International Journal of Recent Technology and Engineering, March 2013, pp. 204-207.

[3] Peng Chang, Ahmadi, Majid, "A High Speed Low Power 4:2 Compressor Cell Design", IEEE International Symposium on Signals, Circuits and Systems, 9-10 July 2009, pp. 1-4.

[4] D. Radhakrishnan, A.P. Preethy, "Low Power CMOS Pass Logic 4-2 Compressor for High-Speed Multiplication", IEEE Midwest Symposium on Circuits and Systems, 8 Auguest 2000, pp. $1296-1298$.

[5] . Vijayasalini. P, Nirmal kumar. R, Dhivya. S. P, Dr. G.M. Tamilselvan, "Design and Analysis of Low Power Multipliers and 4:2 Compressor Using Adiabatic Logic", International Journal of Emerging Technology and Advanced Engineering, January 2013, pp. 288-293.

[6] Jorge Tonfat, Ricardo Reis, "Low Power 3-2 and 4-2 Adder Compressors Implemented Using ASTRAN", South Symposium on Microelectronics, pp.1-6.

[7] Momeni, J. Han, Member, P.Montuschi, Senior Member and F. Lombardi," Design and Analysis of Approximate Compressors for Multiplication", Transactions on Computers, pp.1-13.

[8] Richa Singh, Anjali Sharma, Rohit Singh,“ Power Efficient Design of Multiplexer based Compressor using Adiabatic Logic", International Journal of Computer Applications, November 2013, pp. 45-50. 
[9] Richa Singh, Rajesh Mehra,“ POWER EFFICIENT DESIGN OF MULTIPLEXER USING ADIABATIC LOGIC", International Journal of Advances in Engineering \& Technology, Mar. 2013, pp.246-254

[10] Anand Kumar, "fundamentals of digital circuits", second edition, june 2011. 